\section{Occurrence of Rotenone in Tephrosia macropoda Harv.}

IN an investigation of the contact insecticidal properties of a number of tropical plants, Tattersfield and Gimingham ${ }^{4}$ found that the roots of a specimen of $T$. macropoda Harv. from Natal possessed a definite toxicity to Aphis rumicis. Other members of the genus known to possess insecticidal action have been examined chemically ${ }^{1,2,3,5,6}$, and have been found to contain members of the rotenone group of fish-poisoning compounds. We have recently been able to carry out preliminary tests upon a specimen of $T$. macropoda kindly sent to us by the Natal Herbarium, Department of Agriculture, Durban. The material was collected by Mr. Moses, agronomist attached to the African Explosives and Industries, Ltd.

Qualitative insecticide tests using a cold alcoholic extract of the finely-ground root diluted with saponin solution were made upon Aphis rumicis. At concentrations equivalent to $0 \cdot 25$ and 0.1 per cent of the root, the percentages of moribund and dead insects recorded on the third day after spraying were 95 and 50 per cent respectively. The root thus shows a decided toxic action to this insect.

When an ether extract, amounting to approximately 4 per cent of the root, was taken up in warm carbon tetrachloride and allowed to stand overnight, crystals were deposited. These after recrystallisation from absolute alcohol melted at $162^{\circ} \mathrm{C}$., and showed a methoxyl content of $15 \cdot 75$ per cent. There was no depression of the melting point on admixture with pure rotenone. The rotenone was present to the extent of $0.3-0.4$ per cent of the root. By steam distillation of the resin extracted from the root by means of alcohol, 'tephrosal' was obtained. Other crystalline derivatives of the rotenone group were isolated, but the work is to be extended, and the detailed examination of the roots will be reported later.

It would appear, however, that Tephrosia macropoda, which is to be found to varying extents over the greater part of South-East Africa, merits further investigation of its insecticidal properties, and it may well be that, by selection and suitable cultural means, a sufficiently rich variety could be obtained which would prove of value, particularly for the control of local insect pests.

Dept. of Insecticides and Fungicides, Rothamsted Experimental Station, Harpenden.

\footnotetext{
1 E. P. Clark, J. Amer. Chem. Soc., 52, 2461 (1930). E. P. Clark, Science, 77, 311 (1933). M. Hanriot, C.R., 144, 150 (1907).

F. Tattersfleld and C.T. Gimingham, Ann. App. Biol., 19, 253 (1932)

R. R. Le G. Worsley, Ann. App. Biol., 21, 649 (1934)

- Bull. Imp. Inst., 13, 61 (1915)
}

\section{New Alkaloids of Ergot: Ergosine and Ergosinine}

WE recently reported ${ }^{1}$ the isolation of a new ergot alkaloid which was characterised mainly by its phenolic properties, the m.p. $228^{\circ}$ (decomp.), the specific rotation $[\alpha]_{5161}^{20}+522^{\circ}$ (in chloroform, $c=1$ ), the sparing solubility in methyl alcohol and the ease with which it crystallises. It was assigned a pro. visional formula $\mathrm{C}_{30} \mathrm{H}_{35} \mathrm{O}_{5} \mathrm{~N}_{5}$.

The high dextro rotation suggested that the substance was a member of the group which includes ergotinine, $\psi$-ergotinine, ergotaminine and ergometrinine, all of which have high dextro rotations in chloroform solution, and that like these alkaloids it might be convertible into an isomeric or analogous alkaloid by treatment with acids. This is in fact the case, and the alkaloid, $[\alpha]_{5461}^{20}+522^{\circ}$, for which we propose the name ergosinine has been converted in this way into a new alkaloid with the specific rotation $[\alpha]_{5461}^{20^{\circ}}-194^{\circ}$ (in chloroform, $c=1$ ), for which the name ergosine is suggested. It melts at $228^{\circ}$ (decomp.), retains the phenolic properties of the parent sub. stance and crystallises with ease from a number of solvents. Analyses of the crystalline base are in agreement with the formula $\mathrm{C}_{30} \mathrm{H}_{35} \mathrm{O}_{5} \mathrm{~N}_{5}$, and ergosine and ergosinine are therefore isomeric.

S. SмIтH.

G. M. Trmmis.

Wellcome Chemical Works, Dartford.

May 27.

${ }^{1}$ NATURE, 137, 111 (1936).

\section{Occurrence of Saccocirrus in Western Canada}

THERE appears to be no record of the occurrence of any member of the Archiannelida from the west coast of North America ; indeed any records outside Europe seem to be rare. It is therefore of interest to note the appearance of enormous quantities of a Saccocirrus at Departure Bay, B.C., during the past month. They were first found at a point marking the entrance to the bay from the open Strait of Georgia in the surface layer of a rather coarse sand. bed at the low limit of a low spring tide on April 23. At this time they were so thick in the sand that every cubic inch contained a hundred or so individuals. Mature representatives of both sexes were present. On April 25 there did not seem to be so many, but this may have been due to the fact that the tide did not reach so low a mark. The appearance is the more interesting in that I have visited the beach on which the Saccocirrus was found at the low tides in April, more or less regularly, for the past fifteen years or so, and, to the best of my knowledge, it was never present before.

It is uncertain to what species the specimens should be attributed. In size and in the character of the setæ they correspond to $S$. papillocerus Bobretzky, but the anal lobes resemble those of $S$. major Pierantoni more closely. Possibly they represent an undescribed species.

The only record I have been able to find of the occurrence of a Saccocirrus in the North Pacific area is that by Uchida of $S$. major Pierantoni, from Japan'.

Pacific Biological Station, Nanaimo, B.C. May 13.

1 T. Uchida, Proc. Imp. Acad. Tokyo, 9, 128 (1933).

\section{Heavy Water of Crystallisation}

THE dissociation pressures of copper sulphate pentadeuterate, CuSO ${ }_{4} \cdot 5 \mathrm{D}_{2} \mathrm{O}$, as found by a tensimetric method ${ }^{1}$, are : at $25^{\circ} \mathrm{C}$., $p_{1}=6.655 \mathrm{~mm}$. $\mathrm{Hg}$. at $30^{\circ} \mathrm{C} ., p_{2}=9 \cdot 285 \mathrm{~mm}$. $\mathrm{Hg}$. From these figures 